\title{
Scheduling of Empennage Structure Design Project of Indonesia's Aircraft with Critical Path Method (CPM)
}

\author{
Arin Wulandari, M. Dachyar* and Farizal \\ Industrial Engineering Department, Universitas Indonesia
}

\begin{abstract}
Production of the aircraft becomes very important to facilitate many passengers of aircraft in Indonesia in the future. The design of a very complex aircraft requires proper project management. This study aims to perform the best scheduling project of empennage structure design of Indonesia's aircraft with limited resources. Critical Path Method (CPM) is used to schedule the project based on activity and resource. CPM scheduling results in completion time for activity data for 400 working days. CPM scheduling after assigning human resources results in a longer completion time for 1023.47 working days. CPM scheduling is carried out by reallocating of human resources to produce a shorter completion time, and it results in completion time for 955 working days.
\end{abstract}

\section{Introduction}

Indonesia's need for connectivity with air transport is increasingly high in connecting resources, communities, and industries to protect the country's economy [1]. According to the Air Transport Statistics report of 2015 and 2016, in 2011 to 2016 the number of passenger on domestic destinations has an increasing trend [2], [3]. IATA report (2016) states the number of passenger aircraft in Indonesian is predicted to reach 220 million people in2034[4].

The design of an aircraft is a complex and difficult undertaking to obtain the optimal end product [5]. The complex aircraft design requires proper project scheduling to achieve the project's success. Critical path method (CPM) is a traditional method of project scheduling that results in completion time based on activity and resource.

\section{Literature Review}

A project is a temporary undertaking to create a unique product, service, or outcome [6]. Project management is the universally accepted standard to deal with businesses that are

* Corresponding author: mdachyar@yahoo.com 
temporary, unique, and has a specific purpose [7]. The success of project management can be measured through the "iron triangle" model that includes time, scope, and cost. The model of the iron triangle has a point of view that the project can be successful even though project management was not successful because it has higher goals and long-term[8].Project success should be measured within project scope, scheduling, cost, quality, resource, and risk constraints in term of completing the project [9].

Critical Path Method (CPM) is a method that used to estimate minimum project duration and determine the amount of scheduling flexibility on logical network paths in the schedule model[6]. CPM uses networking forms in project planning to coordinate activities, schedule, and monitor project progress[10]. In the use of CPM, if resources complete an activity before the planned completion date, time can not be disseminated to the next activity[11].

Calculation of critical path includes two stages which areforwardpass calculation and backward pass calculation. The forward pass is a critical path calculation starting from the beginning of the node to the last node in the network. The backward pass is the inverse of the forward pass, the critical path calculation that starts from the end of the node to the initial node in an activity network diagram. The critical path is determined when the forward pass and backward pass has zero slack time.

In the process of network replanning, there is a resource allocation method which is also called as limited resource planning. Resource allocation is an attempt to find the critical path as short as possible based on available or permanent resources. The problem with this method is that employees may not be technically qualified to perform on more than one activity within a network. Unfortunately, not all CPM networks can perform easy resource scheduling. The project manager must make an effort to reallocate resources with the aim of reducing the critical path, provided that the slack time is not planned deliberately as a safety valve[9]. The method to reduce critical path based on the resource is called resource reallocation.

\section{Research Methodology}

Data is collected by deriving secondary data which is a document of the company. The data taken are activity data and human resource data. Activity data consist of project task or activity, duration of the activity, and predecessor of activity. The activity data of the empennage structure design project consists of 55 activities that are divided into seven main activities. The human resources data of the company have requirements for allocation in project scheduling, the distribution of human resources depends on the duration of the project activity.

Data is calculated by critical path method (CPM) to find scheduling of aircraft empennage design project. First, CPM is scheduledwith only activity data by calculating early start (ES), early finish (EF), late start (LS), and late finish (LF) to obtain slack time. The calculation of zero activity slack time is a critical pathon the project. The recent CPM scheduling is then assigned with human resource data to obtain the new critical path. CPM scheduling with activity and human resource data followed by network replanning of human resource reallocation to reduce the critical time of the project. Thecompletion timeof the CPM scheduling can be determined from Gantt chart or the bar form graph. The CPM scheduling results are then analyzed based on the project constraint to measure the project's success. Project constraints used in this study are scheduling based on human resource, cost, and risk.

\section{Results and Discussion}

\subsection{CPM Scheduling based on Activity Data}


Critical activities are determined by calculating the slack time of each activity. Critical activities are obtained when the slack time is equal to zero. The project completion time ofaircraft empennage design project on the activity data is displayed on the part of Gantt chart as in Figure 1.

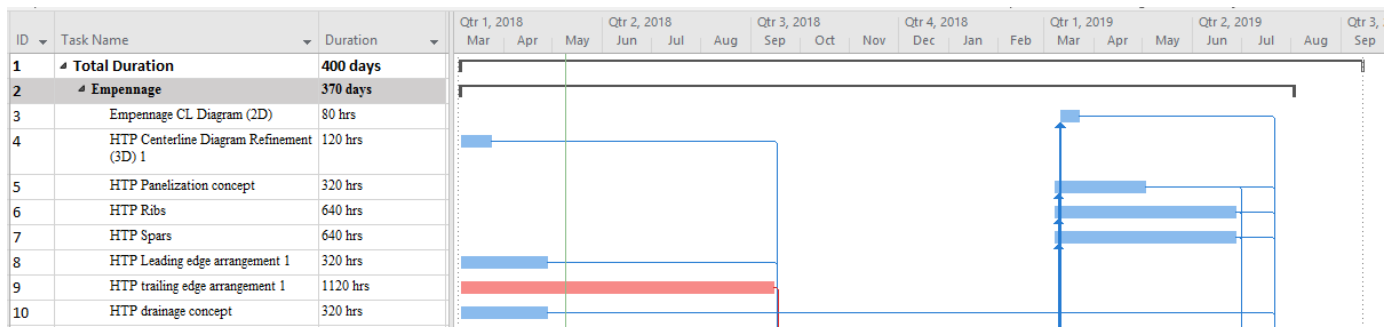

Fig. 1. Gantt Chart 8 Activities of 55 Activitiesin Activity Data

The completion time for CPM scheduling based on activity data is 400 working days. This completion time does not consider the number of human resources working in each activity.

\subsection{CPM Scheduling based on Activity and Human Resource Data}

The data of activity and human resource interconnection is obtained by assigning human resources to each activity. Human resource is assigned to each activity with the requirements that have been described in the data collection phase. Figure 2 illustrates the part of Gantt chart display for activity and human resource activity data.
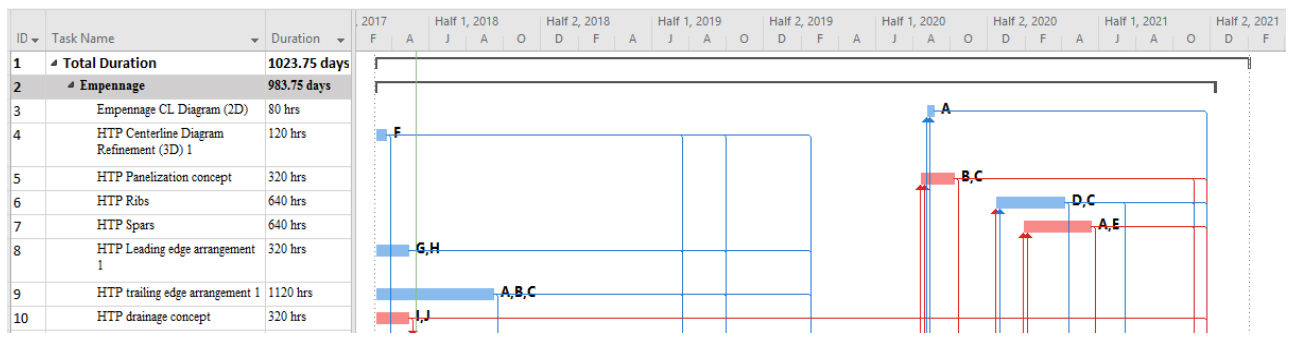

Fig. 2.Gantt Chart 8 Activities of 55 Activities in Activity and Human Resource Data

By assigning human resources on the activity data, there is a change in the order of work activities that cause the completion time of the overall activity is longer which is 1023.75 working days. The number of critical activity on CPM scheduling based on activity and human resource data is 20 activities. Human resources working in CPM scheduling based on activity and human resource data has 64,290 working hours.

\subsection{CPM Scheduling with Human Resource Reallocation}

The completion time of the CPM scheduling results can be shortened by setting up human resource based on resource reallocation. The resource is reallocated by adding human resources to the critical path to reduce time. The number of activity that carried out of human resource reallocation isfive activities. The results of human resource reallocation are three non-critical activities, and two activities that remain critical. Two activities that remain critical are not a problem because the goal of human resource reallocation is not to convert critical activity to non-critical, but to reduce critical time so that the total time of completion 
can be reduced. Table 1 summarizes the critical activities with human resource reallocation and then described the Gantt chart in Figure 3 to see the project completion time.

Table 1. Summary of Critical Activities with Human Resource Reallocation

\begin{tabular}{|l|l|}
\hline No. & Task Name \\
\hline 1 & HTP trailing edge arrangement 1 \\
\hline 2 & HTP drainage concept \\
\hline 3 & HTP Hardpoint \\
\hline 4 & HTP hoisting point definition \\
\hline 5 & VTP trailing edge arrangement 1 \\
\hline 6 & VTP hoisting point definition \\
\hline 7 & Section 538 Subassy \& Panels Breakdowns \\
\hline 8 & Section 538 Frames/Stringers/Longerons Cross Section \& Datum \\
\hline 9 & Empennage Major Assembly Sequence \\
\hline 10 & Catia Filing Database: Empennage \\
\hline 11 & Design Development Management \\
\hline 12 & Design Data Base Control \\
\hline 13 & Structure Design Standards \\
\hline 14 & R80 Aircraft Assembly Sequence Document \\
\hline 15 & 3D System modelling \\
\hline 16 & Material Selection \& Design Allowables \\
\hline
\end{tabular}

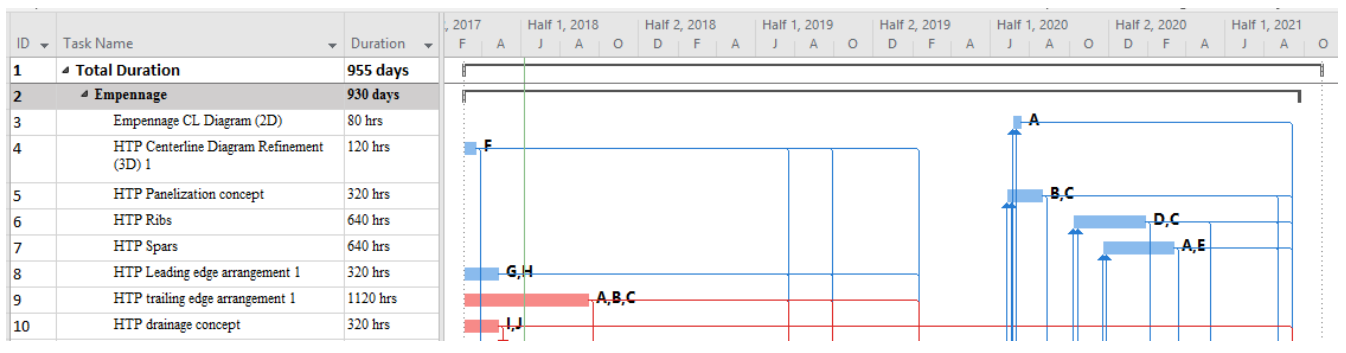

Fig. 3. Gantt Chart 8 Activities of 55 Activities of Activity and Human Resource Data withHuman Resource Reallocation

CPM scheduling with human resource reallocation has a shorter completiontime which is 955 working days. The number of critical activity on CPM scheduling after resource reallocation is 16 activities. Human resources working in CPM scheduling after resource reallocation has 64,290 working hours.

\subsection{Project Constraint}

Project constraints that used in this study are scheduling based on human resource, cost, and risk. Project constraint analysis is performed on CPM scheduling based on activity and human resources data before human resouce reallocation and after human resource reallocation. Before the human resource reallocation, human resources are assigned on CPM scheduling with activity data based on company requirements. CPM scheduling after human resource reallocation process is resetting human resources and it results in the faster completion project time than CPM scheduling before human resource reallocation. Constraint cost in this research is the salary of human resource which seen from the amount of human resource work hour. The incurred cost by CPM scheduling before human resource reallocation is the same as the CPM scheduling after human resource reallocation which is a 
salary for 64,290 working hours. Constraint risk can be seen from the number of critical activities. CPM scheduling before human resource reallocation has a greater number of critical activities than CPM scheduling after human resource reallocation, thus CPM scheduling before human resource reallocation has a higher risk in project implementation.

\section{Conclusion}

Critical Path Method (CPM) is a traditional management project in scheduling that is commonly used for various project. This studyshows three phases of calculating CPM schedulingin empennage design structure projectwhich are CPM scheduling based on activity data, activity and human resource data, and activity and human resource data after resource reallocation. The results of this studyare CPM scheduling based on activity data with completion time for 400 working days, activity and human resources data with completion time for 1023.75 working days, and activity and resource data after resource reallocation with completion time for955 working days. CPM scheduling has a longer completion time when activity data is assigned with human resources because the following activities can be done when the human resources in the previous activity are finished working. The results show that CPM scheduling after human resource reallocation results in faster completion project timeand has a lower risk due to reduced critical activities. The same constraint of CPM scheduling before human resource reallocation and after human resource reallocation is the cost of payroll for 64,290 working days.

Acknowedgement : This research funded by Universitas Indonesia - PITTA 2018

\section{References}

1. U.S. Embassy Jakarta Economic Section, (2012).

2. BPS, (2016).

3. BPS, (2017).

4. IATA, (2016).

5. M. Vignesh, V. K. Morris, and C. Aravind, Springer, (2014).

6. PMI, A Guide to the Project Management Body of Knowledge - PMBOK Guide. (2013).

7. M. Dachyar and Z.A.H. Sanjiwo, Indian J. Sci. Technol.,11,1-8, (2015).

8. M. Radujković and M. Sjekavica, Int. J. Proj. Manag., 196, 607-615, (2017).

9. Project Management Institutes, $A$ guide to the project management body of knowledge (PMBOK guide). (2017).

10. S. Zareei, Renewable and Sustainable Energy Reviews, 81. 756-759, (2018).

11. J. Feng, L. Li, N. Yang, Y. Hong, M. Pang, X. Yao, L. Wang,Water Sci. Eng., 4, 225$236,(2011)$. 